\title{
Microstructural and Micro-textural Evolution during Single Pass High Z-large Strain Deformation of a 0.15C Steel
}

\author{
S. V. S. NARAYANA MURTY, Shiro TORIZUKA and Kotobu NAGAI \\ Metallurgical Processing Group, Steel Research Center, National Institute for Materials Science, Tsukuba 305-0047, Japan. \\ E-mail: susarla.murty@nims.go.jp
}

(Received on January 28, 2005; accepted on July 25, 2005)

\begin{abstract}
Ultrafine grained microstructures and micro-textures formed dynamically during single-pass, high- $Z$, largestrain deformation have been analyzed in $0.15 \mathrm{C}$ steel. A single pass compression technique capable of imposing large plastic strain up to 4 was employed in the present study. Hardness test data revealed work hardening type behavior by pancake type grains while softening behavior was exhibited by equiaxed grains. Detailed micro-texture analysis carried out on the specimens deformed at different temperatures and strains rates in the warm working region revealed no significant difference among them. Even up to fairly high deformation temperatures of $923 \mathrm{~K}$ the texture consists of typical deformation components. Finally, based on the results obtained, fundamentals of ultrafine grained product design are discussed.
\end{abstract}

KEY WORDS: large strain-high Z deformation; warm working; low carbon steel; ultrafine ferrite; ZenerHollomon parameter; misorientation.

\section{Introduction}

Thermo-mechanical processing is an important step in the manufacture of engineering components and is used not only to achieve the required shape but also to impart desired changes in the microstructure and properties. Over the years, refinement of the grain size has been a key objective of the thermo-mechanical processing research. Grain refinement in metallic materials brings about a dramatic improvement in yield strength with simultaneous increase in toughness without the addition of alloying elements. In the context of steel making, Thermo-Mechanical Controlled Processing (TMCP) over the years has evolved rather as a grain refinement technique that can be utilized to obtain a simultaneous improvement in performance and productivity, thus paving new roads for fine grained steels. In recent years, many studies have been conducted on ultrafine grained structures whose grain sizes are smaller than about $1 \mu \mathrm{m}$ with a view to obtain ecologically friendly high performance steels.

Plain carbon steels containing carbon less than $0.2 \mathrm{wt} \%$ have been widely used for structural applications. The microstructure of conventional carbon steels is made of ferrite grains and pearlite colonies, which in turn consists of alternate lamellae of Cementite $\left(\mathrm{Fe}_{3} \mathrm{C}\right)$ and ferrite. There are essentially two potential routes to achieve the grain refinement in these steels. The first one is transformational grain refinement, ${ }^{1-3)}$ wherein the austenite-ferrite transformation is utilized to obtain refined ferrite grains from a prior austenite grain structure. Here, the main purpose of plastic deformation is to increase the density of ferrite nucleation sites by the refinement and flattening of austenite grains.
The second method is recrystallization grain refinement, ${ }^{4,5)}$ wherein the recrystallization of ferrite phase is employed for refining crystal grains from heavily deformed ferrite which may be accomplished by the dynamic recrystallization occurring at warm working temperatures or by subsequent static recrystallization process. In the later case, UFG structure is obtained by large strain deformation of ferrite phase at low temperatures and high strain rates i.e. high $Z$ (Zener-Hollomon parameter) conditions. Ultrafine grained steels in bulk form with microstructures ranging from several nanometers to less than a micron have been fabricated by such severe plastic deformation techniques as mechanical milling with rolling, ${ }^{6,7)}$ equal channel angular pressing (ECAP), ${ }^{8,9)}$ accumulative roll bonding (ARB), ${ }^{10,11)}$ multiple compression $^{12,13)}$ and multi axial and multi stage deformation through warm caliber rolling. ${ }^{14-16)}$ Despite numerous reports on the microstructural investigations on the ferrite refinement, systematic information relating texture with microstructure are limited. ${ }^{17,18)}$ Therefore, it is of interest to systematically study the development of texture as a function of strain which further helps in the understanding of microstructural development during high Z-large strain deformation.

In order to understand microstructural evolution during deformation, stress-strain curves during deformation have been used. Stress-strain curves are classified into work hardening type and dynamic recovery/dynamic recrystallization type. Therefore deformation behavior can be analyzed from the nature of stress-strain curve obtained. However, stress-strain curves obtained from compression test using cylindrical specimens are unsuitable since $50 \%$ compression is said to be the limit of uniform deformation 
beyond which specimen barreling takes place. Therefore, there is no available testing method to obtain stress-strain curve under large strain deformation. Hardness data has been traditionally used to understand the stress-strain data for steels. Therefore, a detailed hardness testing on specimens subjected to various strains will help in understanding the stress-strain behavior and corresponding microstructural variation by high $Z$-large strain deformation.

In view of the above, the aims of the present investigation were: (a) to conduct systematic experiments on a 0.15 carbon steel in the high $Z$ region $\left(10^{12}-10^{16} \mathrm{~s}^{-1}\right)$ and evaluate the hardness as a function of strain to understand microstructural evolution; (b) to study the development of micro-texture as a function of strain at different $Z$ conditions; and (c) to perform detailed grain size analysis of the deformed specimens with a view to establish grain size- $Z$ parameter-microstructure relationship useful for processing of ultrafine grained components.

\section{Experimental}

A large strain single pass, simple compression technique designed and developed in-house is utilized in the present study for conducting the warm deformation studies. In contrast to the other large strain deformation processes where large strains are imposed by multi-pass deformation processes, this technique is a one pass deformation process. This technique thus eliminates the possibility of the sample undergoing complex microstructural changes during static holding/reheating between the passes or avoids the sample undergoing complex multi-axial deformation. In the anvil compression test used in the present study, the imposed strain gets concentrated at the center of the specimen and the strain varies in the range of $0-4$ from the surface to the center of the specimen. This will facilitate the observation of microstructures deformed to various strain levels in a single specimen. The strain distribution across the specimen and the methodology of testing used in the present study were discussed elsewhere in detail. ${ }^{19)}$

In the present study, test specimens having dimensions of 15 long $\times 13$ wide $\times 12$ thick $(\mathrm{mm})$ cut from a hot rolled steel plate of a composition equivalent to SM490 (composition in wt\% C, 0.16; Si, 0.41; Mn, 1.43; P, 0.014; S, 0.004; $\mathrm{Fe}$, Balance) were used. The specimens were machined such that the compression axis is perpendicular to the rolling direction. The initial microstructure was lamellar in which ferrite and pearlite are formed alternatively at substantially equal intervals as shown in Fig. 1. The initial nominal size of ferrite grains was $15 \mu \mathrm{m}$ and the average intervals of pearlite bands was $27 \mu \mathrm{m}$. Using a thermo-mechanical heat treatment simulator capable of controlling the specimen temperature, strain and strain rate under high $Z$ deformation conditions. Figure 2(a) shows the schematic of the testing conditions of heat treatment and deformation conditions employed in the present study. As shown in Fig. 2(a), a specimen was heated to a temperature in the range of 773 to $923 \mathrm{~K}$ which is lower than the $\mathrm{Ac}_{1}$ point (about $993 \mathrm{~K}$ ). Specimens were heated at $5 \mathrm{~K} \mathrm{~s}^{-1}$ to their specified temperature by direct resistance and then compressed in a single stroke after holding at the temperature for $60 \mathrm{~s}$. The compressive deformation was carried out in the time peri-

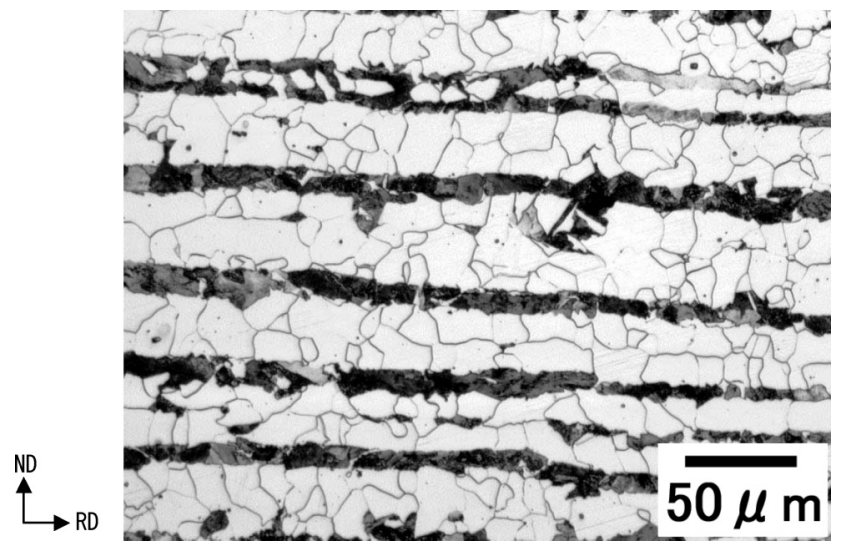

Fig. 1. Optical photomicrograph of the initial microstructure of the steel.
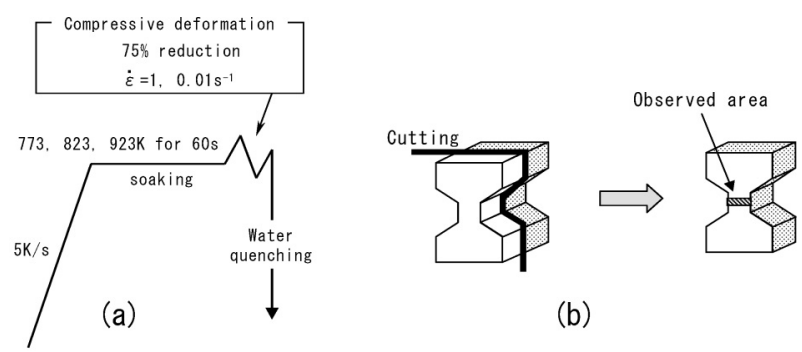

(b)

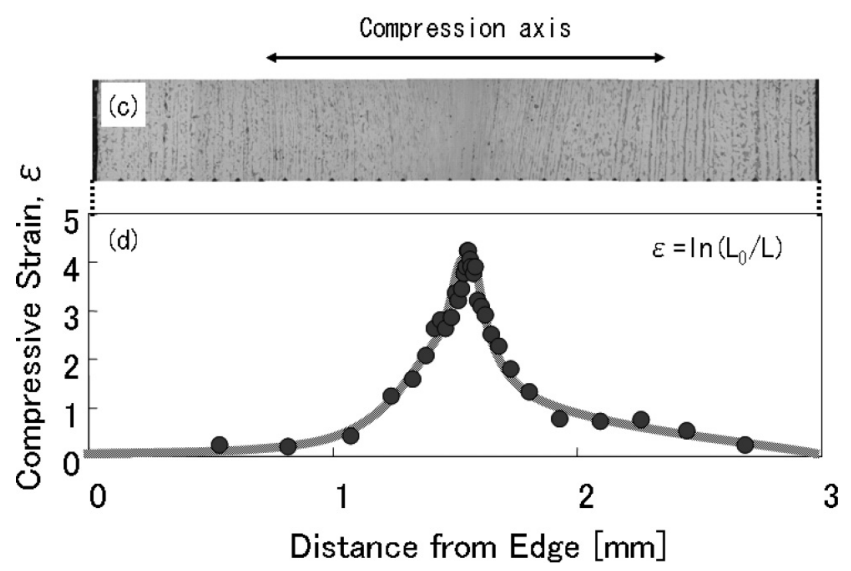

Fig. 2. Schematic illustrations showing (a) the testing conditions of heat treatment and deformation, (b) the anvil compressed specimen and sectioning methodology, (c) optical microstructure of the specimen deformed at $823 \mathrm{~K}$ and a strain rate of $1 \mathrm{~s}^{-1}$, and (d) distribution of the compressive strain through thickness.

ods of $1.38 \mathrm{~s}$ and $138 \mathrm{~s}$ so as to impose apparent nominal strain rates of $1 \mathrm{~s}^{-1}$ and $0.01 \mathrm{~s}^{-1}$, respectively. Immediately after the deformation, the specimens were in-situ waterquenched. Figure 2(b) shows the schematic of the anvil compressed test specimen geometry and sectioning methodology adopted.

Measurement of grain boundary misorientation was carried out using $\mathrm{OIM}^{\mathrm{TM}}$ software (TexSEM Lab Inc. USA) by electron back-scattered diffraction (EBSD) in a Schottky type (Philips XL30 SFEG) scanning electron microscope (SEM) operated at $15 \mathrm{kV}$. For this purpose, the cross section of the deformed specimens was electrolytically polished

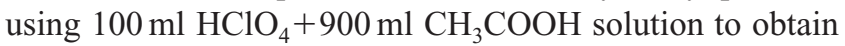
a smooth and flat surface. The measurement of ferrite grain size was carried out from the boundary maps obtained 
through EBSD patterns and includes all grains surrounded by boundaries with misorientation larger than $15^{\circ}$. During the grain size measurement, only grains with aspect ratio $<3$ were considered to avoid deformed/work hardened grains being included. The measurement of the ferrite grain size was carried out from the boundary maps by tracing out the individual grains manually. Nominal grain size was defined as the square root of the average grain area measured.

\section{Results and Discussion}

\subsection{Strain Distribution in the Interior of the Specimen}

In order to obtain good microstructural correlation, at first, it is important to understand the strain distribution within the specimen. In the anvil compression test methodology adopted in the present study, due to the hydrostatic nature of the compressive stress, strain gets concentrated at the center of the specimen and forms a continuous distribution across the interior of the specimen. In the present study, since the microstructure has uniformly stratified pearlite bands at regular intervals, the strain distribution can be computed from the change in the interval of the pearlite bands before and after deformation. The compressive strain $(\varepsilon)$ at any point in the deformed specimen can be determined from:

$$
\varepsilon=\ln \left(\frac{L_{0}}{L}\right)
$$

where $L_{0}$ is the initial interval of the pearlite bands before deformation and $L$ is that after the deformation.

Figure 2(c) shows the optical photomicrograph of the thickness of the specimen deformed at $823 \mathrm{~K}$ and $1 \mathrm{~s}^{-1}$ along with the Vicker's indentation marks at the bottom. It may be noted from the micrograph that the intervals of pearlite bands become narrower from the surface to the center indicating the strain concentration to be at the center. Figure 2(d) shows the distribution of compressive strain determined by Eq. (1) where $L$ is the average of 10 pearlite bands. It can be seen from Fig. 2(d) that the plastic strain varies in the range of 0 to about 4 . It is interesting to note that similar strain distributions were noted for the specimens deformed under other conditions too, indicating that it is precisely possible to observe the microstructures at the desired compressive strain in a single specimen deformed under various processing conditions, thereby drastically reducing the number of tests to be conducted.

\subsection{Effect of Strain on the Development of Ultrafine Grains}

Figure 3 shows the variation of Vickers hardness with compressive strain for specimens deformed under various $Z$ conditions along with the scanning electron micrographs and boundary maps of the deformed specimens to various strains. From the plot shown in Fig. 3, it may be noted that the specimens deformed at $923 \mathrm{~K}$ and $0.01 \mathrm{~s}^{-1}(\log Z=12.5)$ exhibits almost no variation in hardness with compressive strain as noticed by its steady state behavior. On the other hand, specimen deformed at $\log Z=14.2$ exhibits a slight increase in hardness with compressive strain beyond a strain of 1.0. However, at all other testing conditions, the curves exhibit work hardening type behavior with a common general trend being stronger hardening with increasing $Z$ parameter as evidenced by the increasing positive slope of the curves. It may be noted from the figure that within the range of experiments conducted, there is a variation in hardness value of about Hv170 at a strain of 4.

In order to further understand the hardness variation as a function of compressive strain, microstructural analysis as a function of compressive strain is useful. The results of systematic study of microstructures and boundary maps are presented in Fig. 3 as a function of strain for specimens deformed at a temperature of $823 \mathrm{~K}$ and at a strain rate of $1 \mathrm{~s}^{-1}$ (top), and those at $923 \mathrm{~K}$ and $0.01 \mathrm{~s}^{-1}$ (bottom), respectively. Due to the difference in the surface conditions required for these two techniques viz. etched surface for scanning electron microscopy and electropolished surface for EBSD analysis, there is no exact correlation between the SEM photographs and their corresponding boundary maps. Even though, the demarcation between high and low angle grain boundaries can be grossly considered as $15^{\circ}$ misorientation, it was reported ${ }^{5)}$ that a significant fraction of newly generated grains will have at least one side covered by low angle boundary $\left(5^{\circ} \leq \theta<15^{\circ}\right)$. Hence, in the present study, the grain boundaries are distinguished by three colors according to the misorientation, $\theta$. The red line represents the high angle grain boundaries of $\theta \geq 15^{\circ}$. The dark blue and the light blue lines represent low angle grain boundaries of $5^{\circ} \leq \theta<15^{\circ}$ and $1.5^{\circ} \leq \theta<5^{\circ}$, respectively. The presence of a black point in the pattern indicates invalid data where the image quality (IQ) or the confidence index (CI) is too low (IQ $<50$ and $\mathrm{CI}<0.1$ ). Marked on the right hand side of scanning electron micrographs and boundary maps of Fig. 3 in red are the calculated thickness of the pancake ferrite grains at a given strain as per the relationship:

$$
T H_{\alpha}^{\mathrm{c}}=d_{0} \exp (-\varepsilon)
$$

where $T H_{\alpha}^{\mathrm{c}}$, the thickness of the pancake ferrite grain after deformation, $d_{0}$ is the initial ferrite grain size and $\varepsilon$ is the compressive strain imposed.

It may be seen from the boundary maps of specimens deformed at $823 \mathrm{~K}$ and $1 \mathrm{~s}^{-1}$ that as the strain increases, the original grain boundaries are compressed and are elongated in the direction of grain flow resulting in high aspect ratio grains, with the thickness of the grains decreasing with increasing strain. Here, the thickness is defined as the size of a grain parallel to the compression direction. Low angle boundaries are introduced in the original grains as shown in Fig. 3(a), which subdivide the original grains. At a strain of 2.5 , fine equiaxed grains surrounded by high angle grain boundaries (HAGB) may be noticed in Fig. 3(c), which have formed at the boundaries of the original grains. Further, when the strain reaches a value of 4 , significant number of ultrafine grains have formed with the fraction of the HAGBs increasing with strain continuously. A close comparison of boundary maps with the calculated pancake grain thickness shown on the right hand side reveals that the calculated size closely matches the observed size, indicating that the microstructure is essentially a work hardened one without any major reconstitution. Formation of these new ultrafine grains can be explained in terms of 


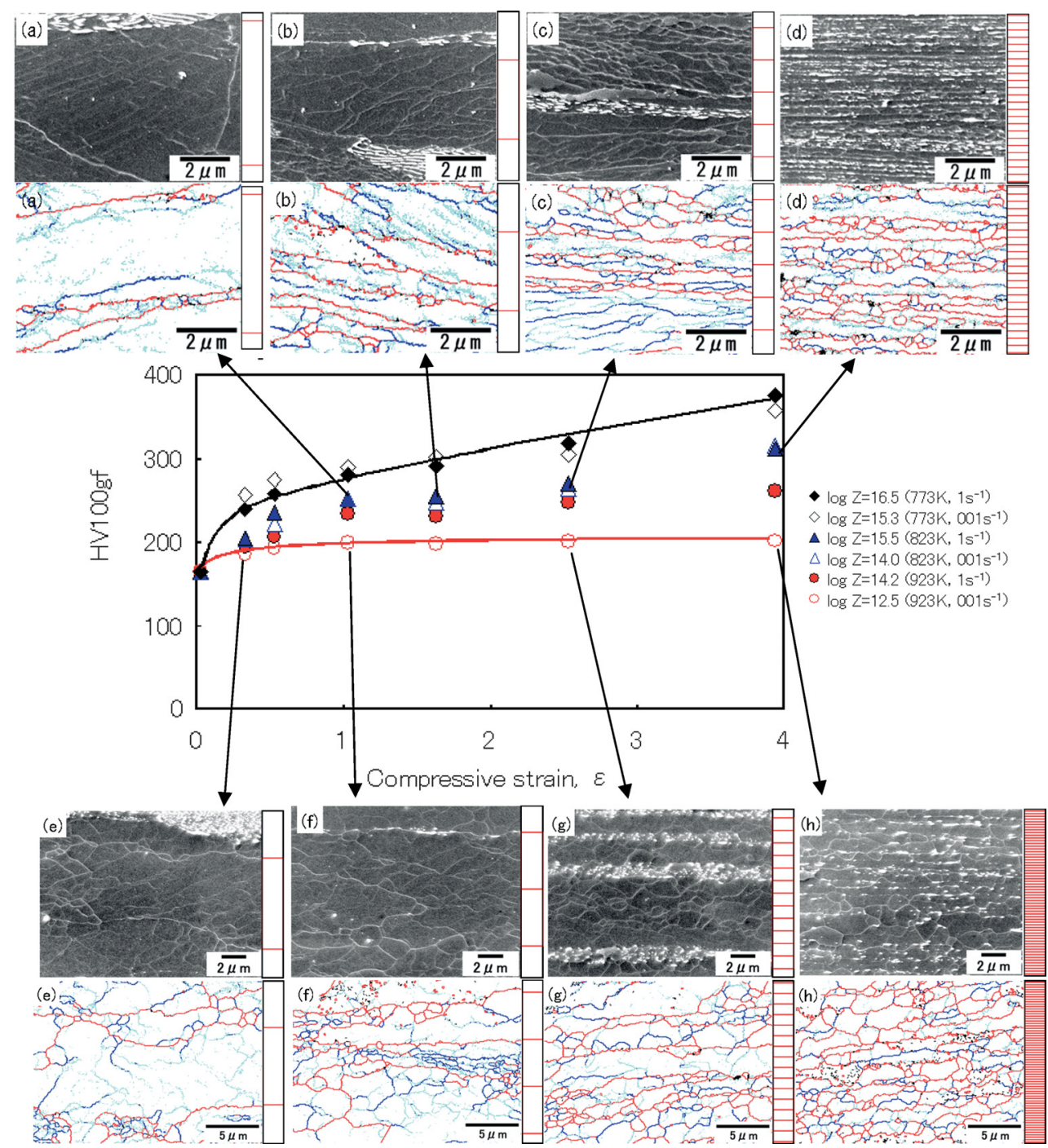

Fig. 3. Variation of Vickers hardness with compressive strain for different specimens subjected to high $Z$ deformation along with the scanning electron micrographs and boundary maps taken (top) for specimen at deformed at $823 \mathrm{~K}_{\text {and }} 1 \mathrm{~s}^{-1}$ ( $\log Z=15.5$ ) at different strains (a) $\varepsilon=1.0$, (b) $\varepsilon=1.6$, (c) $\varepsilon=2.5$ and (d) $\varepsilon=4.0$ and (bottom) for specimen deformed at $923 \mathrm{~K}$ and $0.01 \mathrm{~s}^{-1}(\log Z=12.5)$ at different strains (e) $\varepsilon=0.5$, (f) $\varepsilon=1.0$, (g) $\varepsilon=2.5$ and (h) $\varepsilon=4.0$.

work hardening accompanied with grain subdivision and restoration by dynamic recovery occurring simultaneously at warm working temperatures. Pearlite was found to be segmented and transformed into rows of spheroidized cementite particles (Fig. 3(d)). In other words, even though deformation at $823 \mathrm{~K}$ and $1 \mathrm{~s}^{-1}$ is attributed to work hardening, ultrafine grains are formed through subdivision and/or recovery processes.

Figures 3(c)-3(h) show the microstructural variation with strain for the specimen deformed at $923 \mathrm{~K}$ and $0.01 \mathrm{~s}^{-1}$. At a low strain of 0.5 , the grains are subdivided by the low angle boundaries generated during deformation. It may be noted from Fig. 3(e) that even at the strain of 0.5 , ultrafine grains, though few in number, have formed at the original grain boundaries with their volume fraction increasing with increasing strain. At larger strains, the microstructure consists of equiaxed grains and the observed thickness differs considerably from the predicted thickness. This suggests dynamic recrystallization (DRX) of the microstructure.

From the hardness variation with compressive strain, it can be noted that with increasing $Z$ parameter, there is a transition from steady state behavior (occurring at $\log (Z)=$
$12.5)$ to work hardening type variation $(\log (Z)=16.5)$. The same behavior is noted in microstructural variation from work hardened type (pancake) at high $Z$ values to equiaxed (DRX) grains occurring at low $Z$ values. Based on the above observations, it may be noted that pancake type grains exhibit work hardening type variation with compressive strain and equiaxed grains exhibit steady state behavior and microstructural change noted is in excellent agreement with hardness change. Microstructures at various strains for the specimen deformed at $923 \mathrm{~K}$ and $0.01 \mathrm{~s}^{-1}$ show grain refinement with new equiaxed grains completely eliminating the original grains up to a strain of 4 . However, insignificant change in hardness is noticed beyond a strain of 0.5 . This is especially interesting because, even through the average grain size decreases monotonically with strain, the mechanical property as revealed by hardness does not change significantly. This emphasizes the significant role played by the dislocation structures in the balance of strength and microstructure during warm working.

\subsection{Effect of Strain on the Texture Formation}

Figures $\mathbf{4}$ and $\mathbf{5}$ present the crystallographic orientation 

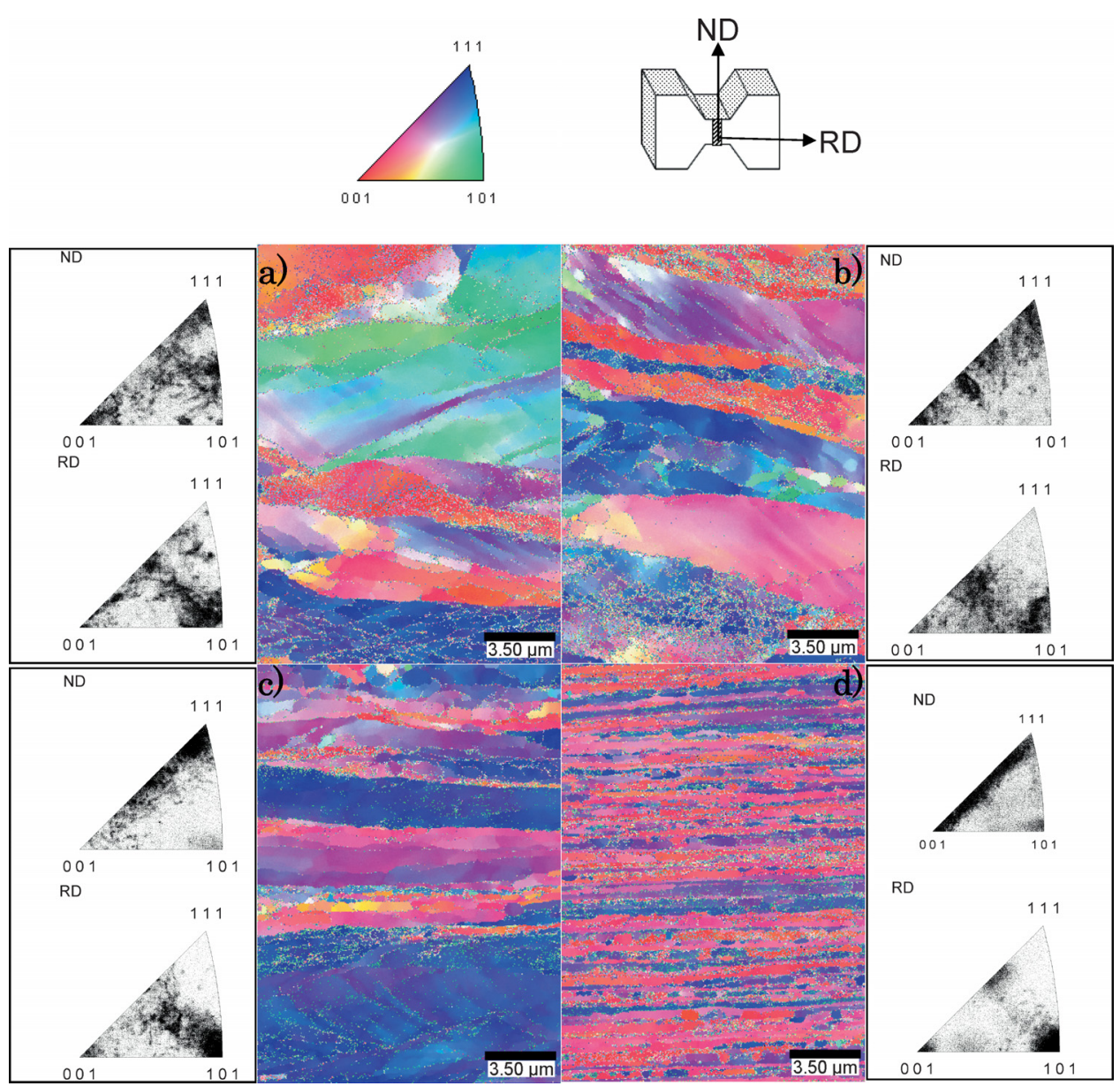

Fig. 4. Orientation maps showing the local orientation distribution along the normal direction (ND) and corresponding inverse pole figures in both normal direction (ND) and along the compression direction (RD) for the specimens deformed at $823 \mathrm{~K}$ and $1 \mathrm{~s}^{-1}$ subjected to a strain of (a) 1.0, (b) 1.6, (c) 2.5 and (d) 4.0 .
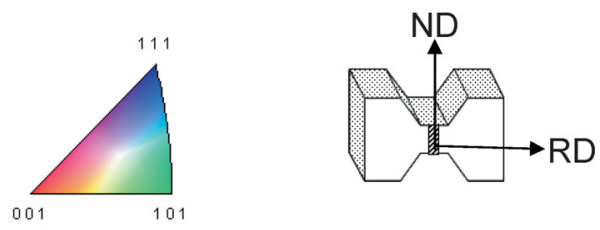

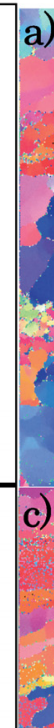

c)

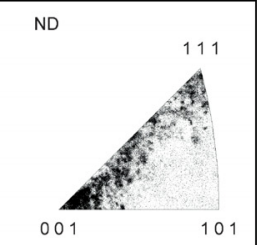

ND

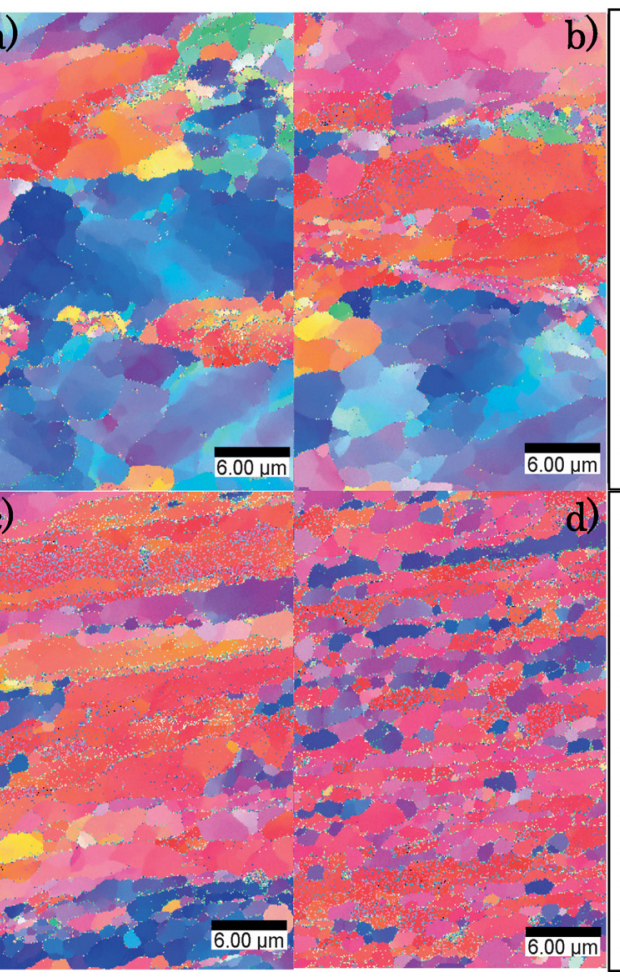

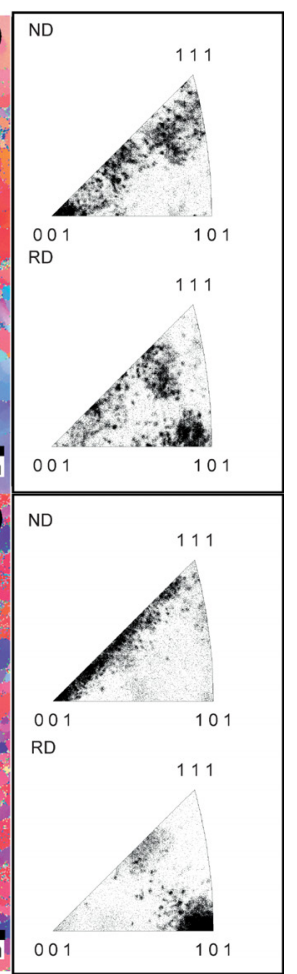

Fig. 5. Orientation maps showing the local orientation distribution along the normal direction (ND) and corresponding inverse pole figures in both normal direction (ND) and along the compression direction (RD) for the specimens deformed at $923 \mathrm{~K}$ and $0.01 \mathrm{~s}^{-1}$ subjected to a strain of (a) 0.5 , (b) 1.0 , (c) 2.5 and (d) 4.0 . 
distribution of local regions by EBSP method and corresponding inverse pole figures (IPF) for the specimens deformed at $823 \mathrm{~K}_{\text {and }} 1 \mathrm{~s}^{-1}$ as well as $923 \mathrm{~K}$ and $0.01 \mathrm{~s}^{-1}$ respectively, as a function of strain. Under both deformation conditions, the orientation images of the ND direction (plate surface normal direction) show that ferrite grain colonies (regions indicated by red color system) with $\{001\}$ parallel to the compressed surface and ferrite grain colonies (regions indicated by blue color system) with $\{111\}$ parallel to the compressed surface have formed in a lamellar shape elongated in the RD direction. Figure 4 shows the orientation maps of the specimen deformed at $823 \mathrm{~K}$ and $1 \mathrm{~s}^{-1}$ to strains of 1.0, 1.6, 2.5 and 4.0 and their corresponding inverse pole figures (adjacent boxes) along ND and RD respectively. It can be seen from Fig. 4(a) that at a low strain of 1.0, the orientation is rather distributed as indicated by the color system. At a strain of 1.6 as shown in Fig. 4(b), micro-bands form within the original grains indicating inhomogeneous deformation. At this stage a significant change in the texture pattern can be seen compared to the previous stage with respect to the orientation as revealed by orientation maps and IPF. At a strain of 2.5, the main texture components are red and blue corresponding to $\{001\}$ and $\{111\}$ respectively (Fig. 4(c). Finally, at a strain of 4.0 , the orientation maps show the standard deformation texture.

On the other hand, Fig. 5 shows the orientation maps of the specimen deformed at $923 \mathrm{~K}$ and $0.01 \mathrm{~s}^{-1}$ to strains of $0.5,1.0,2.5$ and 4.0 and their corresponding inverse pole figures (adjacent boxes) along ND and RD respectively. It can be noted from Fig. 5(a) that even at a low strain of 0.5 , the texture is not random as noted from the orientation map color distribution. However, deformation at $923 \mathrm{~K}$ and $0.01 \mathrm{~s}^{-1}$ (Fig. 5) seems to be more homogeneous compared to the deformation at $823 \mathrm{~K}$ and $1 \mathrm{~s}^{-1}$ (Fig. 4). This is attributed to the higher temperature and lower strain rate of testing. As the deformation proceeds similar texture as seen in the specimen deformed at $823 \mathrm{~K}$ and $1 \mathrm{~s}^{-1}$ develops. However, area fraction of (111) grains indicated by blue color is small in the specimen deformed at $923 \mathrm{~K}, 0.01 \mathrm{~s}^{-1}$ compared to the specimen deformed at $823 \mathrm{~K}, 1 \mathrm{~s}^{-1}$. Detailed quantitative texture analysis is required for clarifying any significant variation in the developed texture in the warm working region.

It is interesting to note from the above studies that no significant qualitative difference has been noticed in the micro-texture developed at large strains in the specimens deformed at $823 \mathrm{~K}$ and $1 \mathrm{~s}^{-1}$ (Fig. 4) as well as $923 \mathrm{~K}$ and $0.01 \mathrm{~s}^{-1}$ (Fig. 5) while the deformation is attributed to work hardening and dynamic recrystallization at these two testing conditions respectively.

\subsection{Microstructural Transition from Work Hardening to Recrystallization}

Hardness variation with compressive strain presented in Fig. 3 clearly showed that as $Z$ parameter decreases, the mechanism of microstructural evolution changes from work hardening to recrystallization. The present authors have studied this transition in detail by representing the test data in $Z$-parameter-compressive strain field ${ }^{20)}$ and classified the microstructures and represented the corresponding bound-

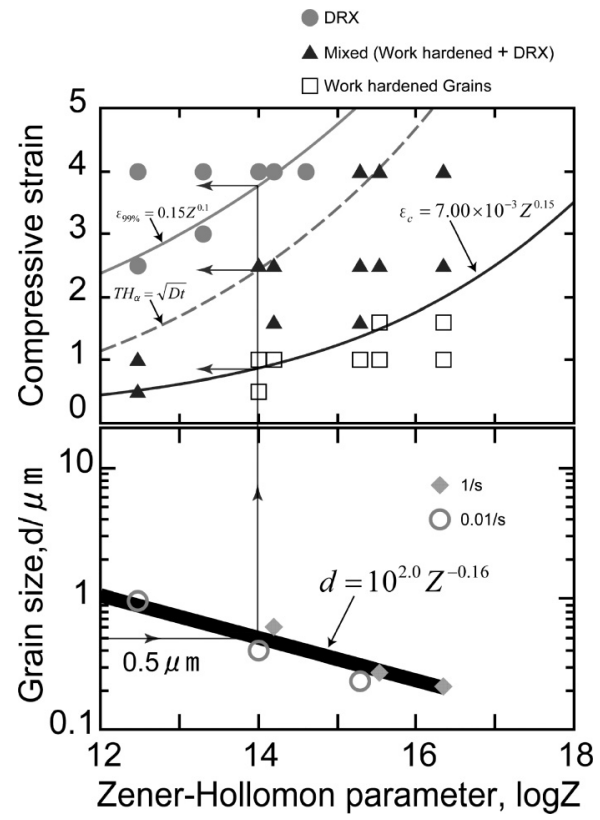

Fig. 6. Compressive strain- $Z$ parameter-grain size plot for high $Z$-large strain deformation of 0.15 Carbon steel. The arrow markings on the figure show an example of the usefulness of this figure in process design to obtain ultrafine grained components with a product grain size of $0.5 \mu \mathrm{m}$.

aries empirically. Figure 6 shows the microstructural manifestations in the $Z$-parameter-compressive strain field along with the grain size variation with $Z$ parameter. This figure includes test data of several specimens deformed at various temperatures and strain rates resulting in a range of $Z$ parameters. It may be noted that the basis for classification of grains is the comparison of the calculated pancake grain thickness $\left(T H_{\alpha}^{\mathrm{c}}\right)$ with that noticed in the boundary maps of the deformed specimens. A careful examination of Fig. 6 indicates that there are three distinct regions based on the microstructural manifestations viz. (I). work hardened grains; (II). mixed grains consisting of work hardened grains and dynamically recrystallized (DRX) grains and (III). DRX grains. The importance of Fig. 6 can be recognized from the fact that it represents the influence of processing variables viz. strain, strain rate and temperature on the microstructural manifestation during large strain warm deformation. Therefore, on one hand, a clear correlation between hardness data and microstructures are established, on the other hand, these observations are in excellent agreement with the above microstructural classifications. Defining large strain deformation as the strain at which the HAGB spacing approaches thermal diffusion distance (or $T H_{\alpha}=(D t)^{1 / 2}$, at the specified deformation temperature and time, the present authors have given a physical meaning to the line representing the $\varepsilon_{99 \%}$ line. ${ }^{21)}$ They attributed microstructural evolution by high Z-large strain deformation to be due to grain boundary diffusion. ${ }^{21)}$

The engineering merit of Fig. 6 can be appreciated by looking from compressive strain- $Z$ parameter-grain size perspective. The most important processing parameters useful in the design of metal forming process are strain, strain rate and temperature to obtain a desired microstructure characterized by a given grain size. As can be seen from 
Fig. 6, strain for obtaining newly developed ultrafine grains by recrystallization increases as the $Z$ parameter increases. In other words, higher strain should be imposed for obtaining ultrafine grains at lower temperatures or higher strain rates. It may also be noted from Fig. 6 that as $Z$ parameter increases, the grain size decreases monotonically. Figure 6 further shows one example of how the experimental data generated in the laboratory can be used for engineering applications on the shop floor. If the desired grain size for a particular application is $0.5 \mu \mathrm{m}$, it gets translated into a $Z$ parameter of $10^{14}$ required to be imposed on the specimen. Now depending on the desired microstructure, the minimum required strain can be noted from the compressive strain- $Z$ parameter plot. Using these details, the process designer has to implement the processing scheme on how to obtain the desired microstructure in the intended geometry. However, it should be noted that this plot depends on the initial microstructure of the steel used. Therefore, from these figures, not only the process parameters such as strain, strain rate and temperature are obtainable for a desired grain size, the microstructure can also be chosen a priori.

\section{Conclusions}

Based on the single pass-large strain-high $Z$ deformation processing experiments conducted on $0.15 \mathrm{C}$ steel specimens and the detailed studies conducted on their microstructure, hardness and micro-texture, the following conclusions are drawn:

(1) Hardness data as a function of compressive strain indicated work hardening behavior in the specimen deformed at $823 \mathrm{~K}$ and $1 \mathrm{~s}^{-1}$, whereas, steady state behavior was noted at $923 \mathrm{~K}$ and $0.01 \mathrm{~s}^{-1}$.

(2) Microstructural transition from work hardening to dynamic recrystallization was noted with increase in $Z$ parameter. Work hardening type hardness variation was exhibited by pancake type grains, while softening behavior was exhibited by equiaxed grains.

(3) No significant difference has been noticed in the micro-textures developed in the specimens deformed at $823 \mathrm{~K}_{\text {and }} 1 \mathrm{~s}^{-1}$ as well as $923 \mathrm{~K}$ and $0.01 \mathrm{~s}^{-1}$, while the de- formation is attributed to work hardening and dynamic recrystallization at these two testing conditions respectively.

(4) Compressive strain- $Z$ parameter plots along with grain size- $Z$ parameter plots help in establishing the processing conditions for obtaining products with a desired microstructure and grain size.

\section{REFERENCES}

1) P. J. Hurley and P. F. Hodgson: Mater. Sci. Technol., 17 (2001), 1360.

2) S. Torizuka and K. Nagai: Mater. Sci. Forum, 426-432 (2003), 4573.

3) J. K. Choi, D. H. Seo, J. S. Lee, K. K. Um and W. Y. Choo: ISIJ Int., 43 (2003), 746.

4) A. Ohmori, S. Torizuka and K. Nagai: Tetsu-to-Hagané, 89 (2003), 31 .

5) A. Ohmori, S. Torizuka and K. Nagai, K. Yamada and Y. Kogo: Tetsu-to-Hagané, 88 (2002), 857.

6) Y. Kimura, S. Suejima, H. Goto and S. Takaki: ISIJ Int., 40 (2000), S174.

7) J. Yin, M. Umemoto, Z. G. Liu and K. Tsuchiya: ISIJ Int., 41 (2001), 1389.

8) V. M. Segal, V. I. Reznikov, A. D. Drobyshevskiy and V. I. Kopylov: Russ. Metall, (1981), 1, 99.

9) D. H. Shin, J. J. Park, S. Y. Chang, Y. K. Lee and K. T. Park: ISIJ Int., 42 (2002), 1490.

10) Y. Saito, H. Utsunomiya, N. Tsuji and T. Sakai: Acta Mater, 47 (1999), 579.

11) N. Tsuji, Y. Saito, H. Utsunomiya and S. Tanigawa: Scr. Mater, 40 (1999), 795.

12) A. Belyakov, T. Sakai and H. Miura: Mater. Trans. JIM, 41 (2000), 476.

13) A. Belyakov, T. Sakai, H. Miura and R. Kaibyshev: ISIJ Int., 39 (1999), 592.

14) A. Ohmori, S. Torizuka, K. Nagai, N. Koseki and Y. Kogo: Tetsu-toHagané, 89 (2003), 781.

15) F. Yin, T. Hanamura, O. Umezawa and K. Nagai: Mater. Sci. Eng. A., A354 (2003), 31.

16) K. Nagai: J. Mater. Process. Technol, 117 (2001), 329.

17) R. Song, D. Ponge, D. Raabe and R. Kaspar: Acta Mater, 53 (2005), 845 .

18) L. Storojeva, D. Ponge, R. Kaspar and D. Raabe: Acta Mater, 52 (2004), 2209

19) S. Torizuka, T. Inoue and K. Nagai: Tetsu-to-Hagané, 86 (2000), 801.

20) S. V. S. Narayana Murty, S. Torizuka, K. Nagai, N. Koseki and Y. Kogo: Scr. Mater., 52 (2005), 713.

21) S. V. S. Narayana Murty, S. Torizuka and K. Nagai: Mater. Sci. Eng. (paper presented at Langdon symposium, TMS, USA) in press. 